\title{
Varenicline (Chantix®) Associated with Increased Cardiovascular Events
}

Researchers from Canada published on-line a study linking varenicline with increased cardiovascular events on December 20, 2017 in the American Journal of Respiratory and Critical Care Medicine (1). They found new varenicline users had a statistically significant $34 \%$ increased incidence of cardiovascular hospitalizations and emergency department visits while taking the medication. This finding was consistent in numerous subgroup and sensitivity analyses with different types of patients, different outcome definitions and different risk and control intervals. They also observed a questionably clinically significant $6 \%$ increase in the incidence of neuropsychiatric hospitalizations. The cardiovascular findings are in contrast to previous studies which reported no difference or a decrease in cardiovascular events $(2,3)$. The authors advise weighing the health benefits of smoking cessation against any potential cardiovascular events related to varenicline.

Richard A. Robbins, MD

Editor, SWJPCC

\section{References}

1. Gershon AS, Campitelli MA, Hawken S, Victor C, Sproule BA, Kurdyak P, Selby $P$. Cardiovascular and neuropsychiatric events following varenicline use for smoking cessation. Am J Respir Crit Care Med. 2017 Dec 20. [Epub ahead of print]. [CrossRef] [PubMed]

2. Kotz D, Viechtbauer W, Simpson C, van Schayck OC, West R, Sheikh A. Cardiovascular and neuropsychiatric risks of varenicline: a retrospective cohort study. Lancet Respir Med. 2015; 3(10):761-8. [CrossRef] [PubMed]

3. Sterling LH, Windle SB, Filion KB, Touma L, Eisenberg MJ. Varenicline and adverse cardiovascular events: a systematic review and meta-analysis of randomized controlled trials. J Am Heart Assoc. 2016; 5(2). pii: e002849. [CrossRef] [PubMed] 